\title{
Clinicopathological Study of Intestinal Tuberculosis \& its Management
}

\author{
M B Islam', M K Rahman ${ }^{2}$, M K Islam ${ }^{3}$, S M Mahmudul $\mathrm{Haq}^{4}$
}

\begin{abstract}
Intestinal tuberculosis is still a common abdominal problems in developing countries like us. Sixty cases of intestinal tuberculosis admitted in the surgical wards of Mymensingh Medical College Hospital over 2 years with different presentations have been studied here, All of them under went through surgical procedures for their management. The age range of the patients was $\mathbf{1 3}$ to $\mathbf{5 5}$ years and most commonly involved age group was 20-40 years. Male to fernale ratio was $1: 1,4,60 \%$ of the patients were in low socio-economic group and $20 \%$ of the patients had got the positive history of contact. $60 \%$ of the patients presented with chronic intestinal obstruction. The most commonly involved site was lleocaecal region in $51.6 \%$ of the patients. Right hemicolectomy with ileotransverse anastomosis was performed commonly $63.3 \%$ of the patients but limited resection and stricturoplasty are also safe and effective procedures.
\end{abstract}

TAJ 2003; 16(1): 24-27

\section{Introduction}

Tuberculosis is still a highly prevalent disease in Bangladesh like any other developing countries of the world where malnutrition, overcrowding and poor sanitary conditions exist. Intestinal tuberculosis also represents a relatively common health problem. Intestinal tuberculosis can affect any part of the alimentary traet from mouth to anus. The site most commonly affected is terminal ileum. We face the problems of intestinal tuberculosis in the form of chronic or acute on chronic intestinal obstruction, symptoms of enteropathy, loss of weight, fever etc. Surgical treatment is required when it causes intestinal obstruction or perforation, A lump in the ileocuecal region, features of sub acute intestinal obstruction, ill health, slight rise of temperature, diarrhoè or constipation with or without concomitant pulmonary uberculosis is the first suspicion of intestinal tuberculosis. As the symptoms and sings of intestinal tuberculosis are non specific and there is no unequivos: diagnostic features either clinically and radiologically. So, some times laparotomy and histopathological examination is needed to establish the diagnosis. Here 60 cases of intestinal tuberculosis presented with various symptoms and signs have been reported. The main focus of this study was epidemiological pbservation, clinical manifestation, diagnosis and trestment of patients with intestinal tuberculosis.

\section{Materials and Methods}

This study was based in the patients admitted in the surgical units of MMCH from Jantuary 1997 to

' Registrar, Surgery Unîl, Rajsnahi Medical College Hospital, Aa shehi)

2 Protessot, Department dol Suroery, Rajshahi Medical College, Rajshani.

a Prolessor. Department at Surgery, Se Salimuliah Madical Coliege. Dhaka.

${ }^{4}$ MO. Surgery Unit it. Rajshan Medicai Colege Hospital. Raishahi 
December 1998, Of them, sixty patients were diagnosed to have intestinal tuberculosis.

Diagnostic criteria included a detailed history, meticulous clinical examination, complete blood count, ESR, Hb\%, mantoux test, $\mathrm{X}$-ray chest. plain $\mathrm{X}$-ray of abdomen. Barium follow-through and Barium enema, laparotomy and histopathological examination of resected specimens. 38 Patients underwent right hemicolectomy with ileotransverse anastomosis, 10 patents underwent only ileotransverse anastomosis without resection of gut. 2 patients underwent stricturoplasty and the remaining 10 patients underwent limited resection and end of end anastomosis of gut.

\section{Results}

Out of total number of cases twenty five (25) were male $(41.6 \%)$ and thirty five $(35)$ were female $(58.3 \%)$ giving male to female ratio $1: 14$. The average age of male and female patients were 27.7 years and 31.1 years respectively.

Table-1: Age distribution of the patients

\begin{tabular}{ccc}
\hline Age (years) & Number of patient & Percentage \\
\hline $10-20$ & 9 & $15 \%$ \\
$21-30$ & 24 & $40 \%$ \\
$31-40$ & 21 & $35 \%$ \\
$41-50$ & 4 & $6.6 \%$ \\
$51-60$ & 2 & $3.3 \%$ \\
Total & 60 & $100 \%$ \\
\hline
\end{tabular}

\section{Presentation}

Out of 60 , thirty six $(60 \%)$ cases presented with chronic intestinal obstruction, six $(10 \%)$ with acute on chronic intestinal obstruction, four $(6.5 \%)$ with acute intestinal obstruction and two (3.3) presented with pneumoperitonium. Four $(6.5 \%)$ initially diagnosed as recurrent appendicitis and the remaining eight $(13.3 \%)$ presented with vague abdominal symptoms. The patients who were initially diagnosed as recurrent appendicitis underwent exploration for appendicectomy but suspicion of intestinal tuberculosis raised on finding enlarged mesenteric lymph nodes and macroscopic nodules on the intestinal wall and omentum. appendicectomy was postponded and biopses were taken from lymph nodes and omentum for subsequent histopathological examination for diagnosis.
Table-2: Presenting symptoms in 60 cases of intestinal TB.

\begin{tabular}{lcc}
\hline Symptoms & No. of case & Percentage \\
\hline Abdominal pain & 50 & $83.3 \%$ \\
Weight loss & 45 & $75 \%$ \\
Fever, malaise and anorexia & 36 & $60.0 \%$ \\
Lump in the abdomen & 24 & $40 \%$ \\
Constipation & 33 & $55 \%$ \\
Diarrhoea altermaling with & 14 & $23.3 \%$ \\
constipation & & \\
Diarrhoea & 10 & $16.6 \%$ \\
Vomiting & 15 & $25 \%$ \\
Cough with expectoration & 9 & $15 \%$ \\
\hline
\end{tabular}

Table-3: Major physical signs in intestinal tuberculosis of 60 cases

\begin{tabular}{lcc}
\hline \multicolumn{1}{c}{ Signs } & Total case & Percentage \\
\hline Pallor & 52 & $86.6 \%$ \\
Abdominal Tenderness & 33 & $55 \%$ \\
Distended abdomen & 38 & $63 \%$ \\
Palpable mass in abulomen & 34 & $53.3 \%$ \\
Visible peristalsis & 27 & $45 \%$ \\
Doughy feeling of abdomeri & 6 & $10 \%$ \\
Ascites & 6 & $10 \%$ \\
Cervical lymphadenopathy & 4 & $60 \%$ \\
Reduced liver dullness & 2 & $3.0 \%$ \\
\hline
\end{tabular}

\section{Investigations}

$\mathrm{CBC}, \mathrm{Hb} \%$ and ESR were done in all patients. Two third of the patients had $\mathrm{Hb} \%$ less than 7.5 $\mathrm{gm} / \mathrm{dl}$ and ESR in the first hour was found ranging between $40-130 \mathrm{~mm}$. Thirty six $(85.57 \%)$ out of 42 patients showed positive (> $10 \mathrm{~mm}$ ) mantoux text and six cases the result was below $10 \mathrm{~mm}$. Xray chest showed only 11 (18.3\%) patients had evidence of old or active pulmonary tuberculosis. In Plain X-ray of abdomen, 36 patients showed signs of intestinal obstruction and two cases showed pneumoperitonium. Batium followthrough was done in 18 cases and Barium enema was done in 10 cases. Of which five calses of Barium follow-through and two cases of Barium enema were reported normal. Pulled up caecum. deformed caecum. irregular narrowing of terminal ileum were most common radilogical findings. Sigmoidoscopy. Colonoscopy. Laparoscopy were not possible due to lack of facilities. But in all cases histopathological examination of resected 
gut, mesentric lymph nodes and omentum were done. Pre-operative diagnoses were changed in many cases on the basis of laparotomy and histopathological findings.

Table-4: laparotomy findings

\begin{tabular}{lcc}
\hline \multicolumn{1}{c}{ laparotomy findings } & No. of case & Percentage \\
\hline Multiple macroscopic nodules & 42 & $70 \%$ \\
Elarged mesenteric lymph mode & 32 & $53.3 \%$ \\
Ascites & 6 & $10 \%$ \\
Ulcerative lesion & 20 & $33.3 \%$ \\
Hyper plastic lesion & 29 & $48.3 \%$ \\
Ulccro-hyperplastic & 12 & $20 \%$ \\
Perforation at terminal ileum & 2 & $3.3 \%$ \\
Inflamed appendix & 2 & $3.3 \%$ \\
Gangrenous small gut & 5 & $8.3 \%$ \\
\hline
\end{tabular}

The sites involved in this series were ileocaecal region $57.6 \%$. ileum $20 \%$, Caecum $11.6 \%$, Colon $10 \%$ and jejunum $5.7 \%$.

Various procedures were performed for treating intestinal tuberculosis in this series. Right hemicolectomy with ileotransverse anastomosis were done in $38(63.3 \%)$ cases.

Table-5: Types of operation

\begin{tabular}{|c|c|c|}
\hline Surgical procedure & Number & Percentage \\
\hline $\begin{array}{l}\text { Right hemicolectomy with } \\
\text { ilcotransverse anastomosis }\end{array}$ & 38 & $63.3 \%$ \\
\hline $\begin{array}{l}\text { Resection of the part of ileum } \\
\text { with ileo-ileal anastomosis }\end{array}$ & 3 & $5.0 \%$ \\
\hline $\begin{array}{l}\text { Resection of the part of jejunum } \\
\text { with jejunojejumal anastomosis }\end{array}$ & 1 & $1.6 \%$ \\
\hline Stricturoplasty & 2 & $3,3 \%$ \\
\hline $\begin{array}{l}\text { Resection of the part of colou } \\
\text { with colocolic anastonosis }\end{array}$ & 6 & $10.0 \%$ \\
\hline Ileotransverse anastomosis & 10 & $16.6 \%$ \\
\hline
\end{tabular}

It is notable only ileotransverse anastomosis without resection of gut was done in $10(16.6 \%)$ cakes. This was done because the patients had very poot general conditions and they presented with acute intestinal obstruction. Stricturoplasty done in short segment stricture involving jejunum.

Antituberculous chemotherapy stared in the hospital and advised to continue for 12 months in all cases. Most of the patients were relieved from pre-operative symptoms. Oniy one patient developed wound dehiscence and four developed minor wound infection. With in 6 months of follow up all of them found alright.

\section{Discussion}

Intestinal tuberculosis is not an uncommon clinical problem in developing countries and atso reemerging in the developed countries due to its association with acquired immunodeficiency syndrome (AIDS). Hundred (100) years have passed since the indentification of the organism by Robert Koch in March 24, 1882. Still the disease is a worldwide problem. Intestinal tuberculosis is an important cause of morbidity in the Indian population, because the diagnosis is delayed? Shukla and Hughes rightly termed intestinal tuberculosis is a continuing problem ${ }^{3}$.

In our country no statistical is available regarding intestinal tuberculosis. But the incidence should be fairly significant because of a great number of people have been suffering from pulmonary T.B of which a good numbers received no or inadequate treatment, In India, about $3 \%$ to $20 \%$ of all intestinal obstructions are due to tuberculosis of the abdomen in various forms ${ }^{4}$. Sex incidence in this series $F: M=1,4: 1$. Prakash et al showed that $\mathrm{F}: \mathrm{M}=2: 1$, Hughes and shukla reported $\mathrm{F}: \mathrm{M}]$ 1.6:1.17 and Gupta et al also reported the ratio was $2.5: 1.22$. The reason for female predominance is likely that they are not exposed to medicare as the males. Average of the patents are 28.9 years. Prakash et al showed the average age incidence was 29.5 years $^{5}$. In Rauf's (1984) series average age of the patients was 31.6 years and in Mahboob's (1995) series it was 26.5 years ${ }^{6}$. Bently et al showed that the average age among their patients was 63 years? These patients were Britons. Several studies in our country also showed tubercular enteritis is a disease of young adolescents and adults. Intestinal tuberculosis is common among the people of low socio-economic group. Banerjee B.N. had shown that the incidence was more among the refugees living in slums of calcutta $+20 \%$ of the patient of this series had positive history of contact. Reports from India showed that history of positive contact varies from $5 \%$ to $25 \%$. (Prakash et al 1978, vaidya and Sodhi et al 1978 and Banerjee et al 1956). In Rouf's (1982) series $18.5 \%$ of the patient had positive history of contact. $18 \%$ of the patients in this series had co-existing pulmonary tuberculosis. According to S sircar and V A Janjela et al only $16 \%$ of the patients of Intestinal tuberculosis were 
found to have co-existing pulmonary tuberculosis ${ }^{2}$. Abdominal pain was the commonest $(83,3 \%)$ symptom. Followed by tubercular toxaemia ( $60 \%)$ and lump in right iliac fossa $(53.3 \%)$. Contrary to the popular believe the characteristic "doughy feel" of the abdomen was found only in $10 \%$ of the cases in this series. In a series from South Africa they found "Doughy feel" of the abdomen only in $8 \%$ cases. $^{9}$. A moderate degree of anaemia and raised ESR were commonest haematological findings. Mantoux test was positive in $80 \%$ of the patient. Rauf reported $91.5 \%$ and prokash at al reported $92 \%$ positive result ${ }^{8,5}$. A negative mantoux test does not exclude tuberculosis.

There are variations in ideas regarding surgical treatment of intestinal tuberculosis. Bypass surgery was frequently advocated in the past ${ }^{\text {to }}$ but long term results were not very good and blind loop syndrome was one of its main disadvantage. Bhansali even suggested that bypass patient should be subjected to a secondary excisional procedure when conditions are favourable ${ }^{1 t}$. Definitive surgery where possible to be done even in the emergency cases ${ }^{12}$. Right hemicolectomy with ileotransverse anaestomosis is commonly performed for ileocaecal tuberculosis and it is safe and effective procedure. Stricturoplasty introduced by katayara in 1977 is a good procedure where possible $^{13}$. Post operatively all patients were administered anti tuberculous chemotherapy.

\section{Conclusion}

From our study, we can conclude that the signs and symptoms of intestinal tuberculosis are protean and nonspecific, and there is no unequivocal diagnostic features either clinically or radiologically. As a result, laparotomy and histopathological examination are frequently necessary to establish confirmatory diagnosis.

Right hemicolectomy with ileotransverse anastomosis is most commonly performed proudure. But limited resection and stricturoplasty are also safe and effective procedure.
Moreover for prevention of intestinal tuberculosis measures such as immunization against tuberculosis, effective and adequate treatment of pulmonary tuberculosis and cervical tubercular lymphadenitis, pasterization of milk, improved standard of living and prevention of over crowding can be adapted.

\section{References}

1. Neil M. The small \& large intestine: in Mann CV. Russel RCG, William Norman S. (ed) Bailey \& Lave Short Practice of Surgery. 22nd ed. London, Chapman \& Hall. 1995; 781-809.

2. Sircar $S$, Tanija VA. Diagnosis of intestinal tuberculosis JIMA. 1996; 94(9): 342-4.

3. Shukla H, Hughes LE, Abdominal tuberculosis in 1970's: a continuing problem. Br J Surg . 1978: $65: 403-405$.

4. Banerjee BN. Chronic hypertropic ileocaecal tuberculosis, Ind J Surg. 1950; 12:33-41

5. Prokash AU. Constriclive tuberculosis of the bowel; Inter Surg . 1978; 63: 23-9.

6. Mahaboob-E.Haseeb Shaharyar Sabet. Abdominal tuberculosis in 30 cases (FCPS dissertation). BCPS, Dhaka.1985.

7. Bently G, Webstere JHH Gastroinlestinai tuberculosis - a 10 years review. British journal Surgery , 1967; 54:90-96,

8. Rouf HMA. Problems of intestinal tuberculosis in Bangladesh: cases study and review (FCPS dissertation). BCPS, Dhaka. 1982.

9. Das SHS. Clinical diagnosis of Abdominal tuberculosis. Br J Surg .1976;63:941-6.

10. Davis AA. Tuberculosis of alimentary tract. Surg, Gyn. and Obst. 1933; 56:907-910.

11. Bhansali SK. Abdominal tuberculosis. Ann $d$ Gastroenterol .1977;67:324-37.

12. Anand SS, Pathak IC. Surgical treatment Abdominal tuberculosis, with special references to ileocaecal tuberculosis. 1961:JiMA. 37, 423-427.

13. Katariya, BN et al. Stricturoplasty for tubercular stricture of the gastrointestinal tract, $\mathrm{Br} J$ Surg. $1977: 64: 496-498$.

Ail corresponderice to: MB isiam

Registrar, Surgery Unit 1 . Rajshahi Medical College Hospital, Rajshahi 